Article

\title{
An Intelligent Optimization Method for Vortex-Induced Vibration Reducing and Performance Improving in a Large Francis Turbine
}

\author{
Xuanlin Peng ${ }^{1,2, *}\left(\mathbb{D}\right.$, Jianzhong Zhou ${ }^{1,2, *}$, Chu Zhang ${ }^{1,2}$, Ruhai Li ${ }^{1,2}$, Yanhe $\mathrm{Xu}^{1,2}$ and \\ Diyi Chen ${ }^{3}$ \\ 1 School of Hydropower and Information Engineering, Huazhong University of Science and Technology, \\ Wuhan 430074, China; zhangchuhust@foxmail.com (C.Z.); D201577803@hust.edu.cn (R.L.); \\ yh_xu@hust.edu.cn (Y.X.) \\ 2 Hubei Key Laboratory of Digital Valley Science and Technology, Huazhong University of Science and \\ Technology, Wuhan 430074, China \\ 3 Institute of Water Resources and Hydropower Research, Northwest A\&F University, Yangling 712100, China; \\ diyichen@nwsuaf.edu.cn \\ * $\quad$ Correspondence: pengx10924@hust.edu.cn (X.P.); jz.zhou@hust.edu.cn (J.Z.); Tel.: +86-0736-275-2601 (X.P.); \\ +86-027-8754-3127 (J.Z.)
}

Received: 14 October 2017; Accepted: 12 November 2017; Published: 19 November 2017

\begin{abstract}
In this paper, a new methodology is proposed to reduce the vortex-induced vibration (VIV) and improve the performance of the stay vane in a 200-MW Francis turbine. The process can be divided into two parts. Firstly, a diagnosis method for stay vane vibration based on field experiments and a finite element method (FEM) is presented. It is found that the resonance between the Kármán vortex and the stay vane is the main cause for the undesired vibration. Then, we focus on establishing an intelligent optimization model of the stay vane's trailing edge profile. To this end, an approach combining factorial experiments, extreme learning machine (ELM) and particle swarm optimization (PSO) is implemented. Three kinds of improved profiles of the stay vane are proposed and compared. Finally, the profile with a Donaldson trailing edge is adopted as the best solution for the stay vane, and verifications such as computational fluid dynamics (CFD) simulations, structural analysis and fatigue analysis are performed to validate the optimized geometry.
\end{abstract}

Keywords: intelligent optimization method; stay vane; vortex-induced vibration (VIV); extreme learning machine (ELM); computational fluid dynamics (CFD)

\section{Introduction}

Since the Francis turbine is large-scale fluid machinery, its hydraulic factors always turn out to be one of the main causes of vibration in the hydropower units. The hydraulic factors can be classified into three categories: the low-frequency pressure pulsation in the draft tube appeared under the condition of partial load; the pressure pulsation in the runner caused by channel vortex when the turbine deviate from the optimum working condition; and the high-frequency pressure pulsation discovered at the end of stay vanes, guide vanes and the runner blade, which is caused by Kármán vortex [1]. The Kármán vortex refers to the two counter-rotating rows of swirls, which alternately fall off at the tail of the nonlinear object when fluid flows past [2]. It can produce periodic forces on the object causing periodic vibration, especially when the vortex shedding frequency coincides with one of the natural frequencies of the vane, threatening resonance occurs, which will lead to more violent vibration and potentially initiating cracks [3,4]. The resonance induced by the Kármán vortex not only disturbs the downstream flow, resulting efficiency reduction and leading to channel vortex, but 
also causes serious damage to the unit components $[5,6]$. Therefore, it is very important to carry out theoretical research and an engineering investigation of the Kármán vortex resonance in a large-scale turbine, which is very meaningful for the antivibration and anticracking of a hydropower unit.

Numerical method is an effective means in turbulence phenomena study. For example, Viviano and Musumeci et al. [7-9] proposed simplified numerical models, which simulate turbulence by means of eddy viscosity formulation, to study the mechanism of waves. But when it comes to optimal design, computational fluid dynamics (CFD) turns out to be a better choice because it is more practical and it can overcome the limitations of experimental conditions [10-18]. For instance, Zhang et al. [10] performed an investigation of two degrees of freedom on vortex-induced vibration under the wakes interference of an oscillating airfoil. By taking the advantage of the CFD technology, a variety of wakes generated by an oscillating airfoil at a different frequency and amplitude of the oscillation, including the Kármán wake, inverted Kármán wake, $2 \mathrm{P}$ wake, and the $2 \mathrm{P}+2 \mathrm{~S}$ wake have been studied numerically. Thapa et al. [11] proposed a CFD-based optimization method for the hydraulic design of the guide vane cascade instead of the costly physical model experiment. The performance of the guide vane cascade was improved without disturbing the flow condition of the runner inlet, and the results were validated with particle image velocimetry (PIV) method.

There are many studies that have investigated the vibration induced by vortex (VIV) of hydrofoil using CFD and experimental method. Zobeiri et al. [19] focused on the VIV of the hydrofoil with oblique trailing edge at high Reynolds number, and concluded that the collision between upper and lower vortices and the resulting vorticity redistribution are the main reasons of the vibration reduction. Yao et al. [20] carried out a research on the effect of trailing edge shape on hydrodynamic damping for a hydrofoil. Numerical simulations and experiments were performed on the hydrofoils with a Blunt trailing edge and a Donaldson trailing edge. As a typical hydrofoil, the stay vane in large-scale Francis turbine was designed slender in the direction normal to the flow and has a relatively thick trailing edge for the purpose of hydraulic efficiency. As a result, structural vibration is very likely to be excited by the Kármán vortex in the wake of stay vanes. Neto et al. [21] studied the 2D flow around 13 kinds of similar stay vane profiles with different trailing edge geometries to investigate the main characteristics of the excitation forces for each one of them and their respective dynamic behaviors. Vu et al. [22] presented a CFD methodology to predict the Kármán vortex shedding frequency of the turbine stay vane by means of $2 \mathrm{D}$ unsteady state computation. The accuracy of the method has been validated against experimental data obtained with model size from laboratory and with prototype size from site. It concluded that the frequency and amplitude of the VIV is highly dependent on the stream velocity and the trailing edge profile. Neto et al. [23] performed an investigation aimed at eliminating the reoccurrence of cracks on the stay vanes without affecting the availability of the machine in the process. The performance of stay vane was improved by the modified geometry, which is based on previous experiences and references. However, the researchers did not have a systematic and comprehensive study on the effect of the trailing edge profile of the stay vane on VIV, nor proposed a scientific and rigorous remedy of reducing the vibration.

In this work, the stay vanes of a large hydropower unit are the investigated object, which encountered serious vibration and some of them even produced cracks during practical operation. Aiming to eliminate the resonance and reduce the vibration, an intelligent optimization method based on two-dimensional CFD simulations, artificial neural networks (ANN), and PSO was employed to improve the geometries of the stay vane. Site experimental tests were implemented to validate the CFD model, and to ensure the quality of results, the mechanical strength and fatigue life of optimal designs were also evaluated by 3-dimensional numerical simulations.

\section{Methodology}

The investigated object is a large-scale Francis turbine that has been put into operation for years. Penetrating cracks, which are usually considered as a consequence of the severe vibration brought by the Kármán vortex, were found on the stay vanes during the maintenance of this hydropower 
unit (Table 1). To eliminate the violent vibration and improve the performance of the stay vane, an optimal process was undertaken. Firstly, a numerical model was established to study the mechanism of the vibration on stay vanes, which was validated with site experiments of the large hydropower unit. Secondly, an optimization process based on the CFD numerical model, ANN, and PSO was utilized to optimize the stay vane profile. Detailed explanations of this process are displayed in the following parts.

Table 1. Crack detection results of stay vanes.

\begin{tabular}{|c|c|c|c|}
\hline Groups & Number & Basic Shape Parameters of the Stay Vane & Cracks \\
\hline \multirow[t]{2}{*}{1} & No. $1-8,24$ & - & \multirow[t]{2}{*}{ Penetrating cracks } \\
\hline & & \#1 \#8,\#24 & \\
\hline \multirow[t]{2}{*}{2} & No. 9-19 & 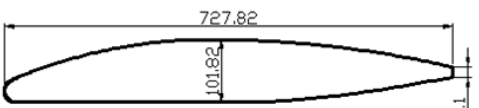 & \multirow[t]{2}{*}{ Incipient Cracks } \\
\hline & & $\# 9 \sim \# 19$ & \\
\hline \multirow[t]{2}{*}{3} & No. $20-22$ & $\begin{array}{l}597.46 \\
0 \\
0 \\
0 \\
0\end{array}$ & \multirow[t]{2}{*}{ No Cracks } \\
\hline & & $\# \subset 0 \sim \# ट C$ & \\
\hline 4 & No. 23 & $\frac{538.76}{\text { 离 }}$ & No Cracks \\
\hline
\end{tabular}

\subsection{The Definition of Flow Simulation}

Since the most damaged stay vane were found in the Group 1, the simulation model was established according to the profile of stay vanes in Group 1 . A high-quality mesh is required at the first place of flow simulation. The computational model was divided into the parts (the monitoring point, denoted in Figure 1, is $200 \mathrm{~mm}$ behind the vanes), and each part was discretized by an unstructured mesh with triangular elements. The mesh of the turbulence zone and the boundary layer zone was refined in order to improve the accuracy and the numerical convergence of the analysis. Moreover, the automatic near-wall treatment approach was implemented to reduce the mesh sensitivity in the low Reynolds number zones.

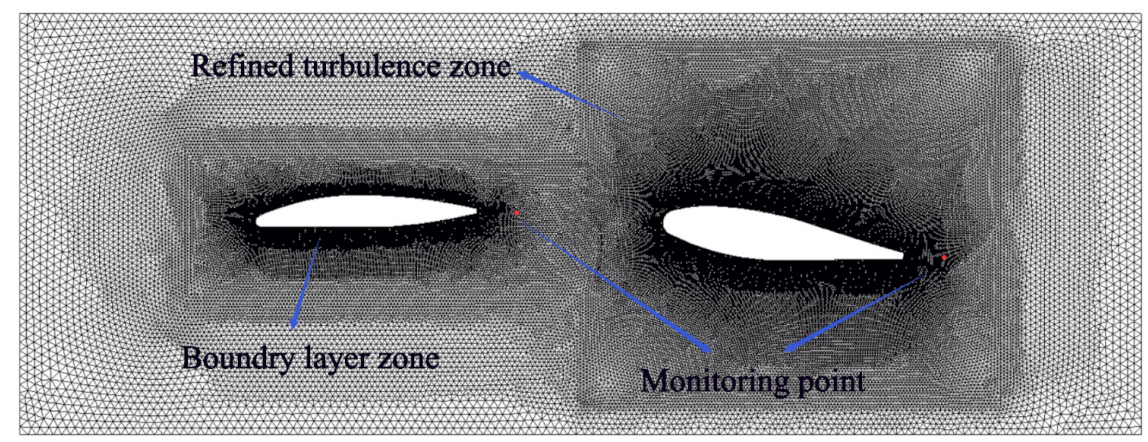

Figure 1. Mesh of the tandem cascade structure.

To guarantee the mesh independence, six simulations were performed by taking the dynamic pressure behind the stay vane and guide vane as the reference variables (Figure 2). It can be observed that the difference between the last three results is less than $4 \%$. Hence, the mesh size with 269,672 elements was chosen in later analysis to cut down the computational cost since the 
computational time is positively correlated to the element number of mesh. The average value of $y+$ obtained in the regions of the vanes was 1.2 , which is considered as an appropriate value $[24,25]$.

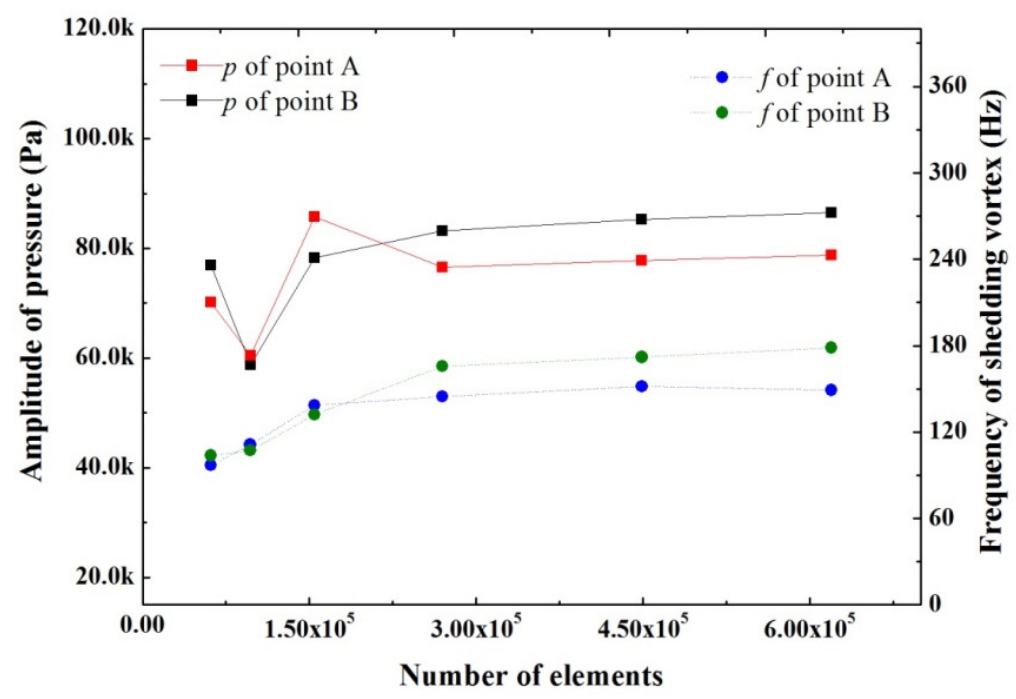

Figure 2. Mesh independence verification.

The simulation was performed using the commercial software: ANSYS Fluent. Since the Kármán vortex-shedding phenomenon is significantly influenced by the thickness of boundary layer at the trailing edge, it is important to obtain a good boundary layer resolution for an accurate prediction. Two different turbulence models were employed in the simulations to approach the practical situation: The Shear Stress Transport $k-w$ model (SST $k-w$ ), which retains the features of the original $k-w$ model in the near wall area and uses $k-w$ model away from the wall, is considered as a suitable turbulence model to investigate the flow separation phenomenon [25], and the large eddy simulation model (LES), which can capture subtle movements under unsteady state and overcome the huge computational cost brought by the direct numerical simulations (DNS) at the same time, is considered to be the most promising turbulence numerical simulation development direction [26]. Strictly speaking, the vortex shedding is a three-dimensional phenomenon [21], but the adopted 2D approach at the design stage is considered competent for mechanism study.

The boundary conditions of inlet and outlet were set as velocity-inlet and outflow respectively, and time step $\Delta t$ was set as $0.0005 \mathrm{~s}$. The governing equation for flow was solved by the finite volume method (FVM) with the semi-implicit method for pressure-linked equations (SIMPLE) algorithm. In the discretization of the equations, a high-resolution MUSL (monotone upstream-centered schemes for conservation laws) for the advection terms and diffusion term was implemented. In order to avoid misconvergence and instability during the iteration process, the under-relaxation iteration technique is adopted, and the maximum residual error of the convergence condition is less than 0.001 .

\subsection{Improvement of the Trailing Edge}

Considering that the resonance between the stay vane and the shedding vortex is the main cause of vibration and fatigue failure, the improvement of the trailing edge of the stay vane should be carried out from two aspects: change the frequency of shedding vortex and reduce the energy of the vortex street. The elementary improvement of trailing edge of the stay vane was based on three or four factors (shape, oblique angle, thickness, fillet radius, arc radius), which strongly influence the VIV. These factors can basically identify the configuration of trailing edge, and each factor was analyzed using control variate method. All the simulations were configured in the same way described in the former sections. 
The original profile of the trailing edge is the so-called blunt trailing edge (Figure 1). The profiles of three kinds of improved trailing edges are shown respectively in Figure 3, where $\alpha$ is the oblique angle, $T$ is the thickness, and $r$ and $R$ stand for fillet and arc radius respectively.

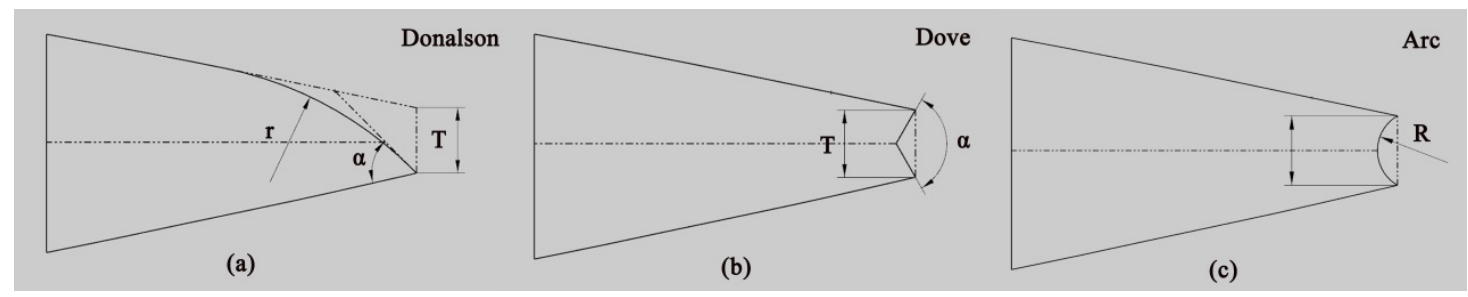

Figure 3. Profiles of improved trailing edges: (a) Donaldson trailing edge; (b) Dove trailing edge; and (c) Arc trailing edge.

\subsection{The Trailing Edge Optimization}

Inspired by the work of [25], an intelligent optimization model of the trailing edge of the stay vane was developed utilizing a new methodology combines CFD simulations, ANN and PSO optimization. Figure 4 shows the schematic procedure of the optimization.

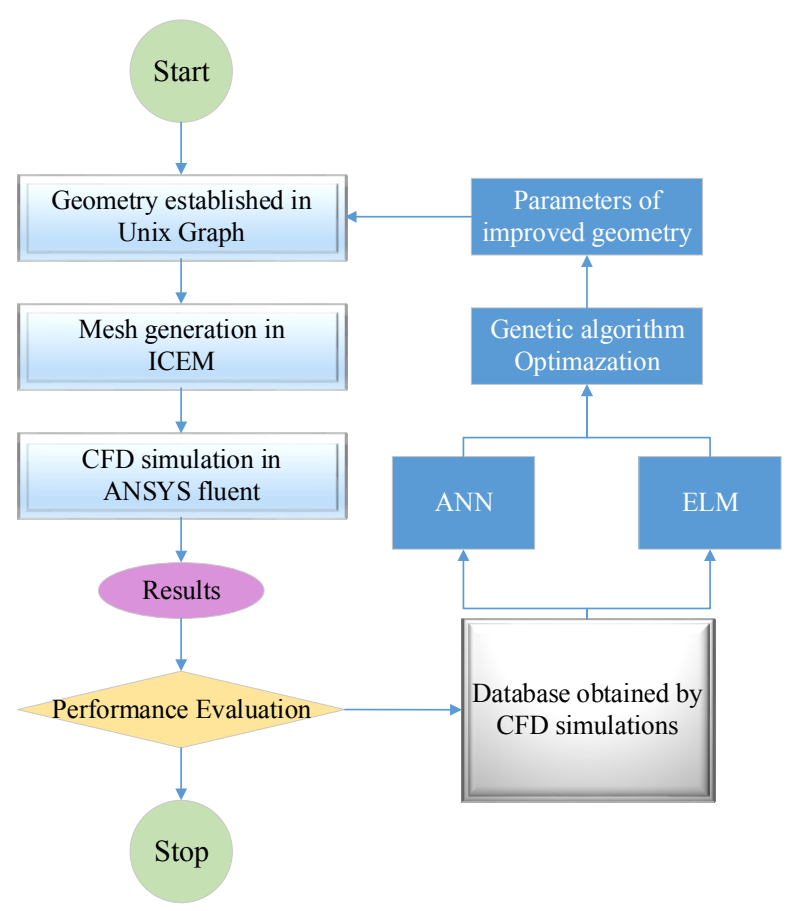

Figure 4. Schematic procedure of trailing edge optimization.

The process begins with the geometric model, which was parametrically modelled in the software Unigraphics NX (UG NX 10.0, Siemens PLM Software, Plano, TX, USA). The next step is mesh generation in ICEM and CFD simulation in ANSYS fluent. An objective function (OF) based on the requirements of vibration and other performance was defined to evaluate the performance of the profile of the stay vane. The original database was generated through the former factorial experiments based on the work of [27], which were related to the four parameters that defined the trailing edge of the geometry (displayed in Figure 3). If the requirements were not satisfied, the process was to continue with database generation. The information in the database was utilized in ANN's training, which can predict the performance more efficiently than the time-consuming CFD 
simulations. Then PSO optimization was employed to seek for the parameters corresponded with better performance. The obtained results were used to generate new optimal geometry. If the optimal performance cannot fulfill the requirement, the geometry would be added to the database, and a new process with ANN training and PSO optimization began.

\subsubsection{Objective Function (OF)}

In order to seek for better profile of the stay vane, an OF was introduced to evaluate the performance of different geometries. At the design stage, the principal requirement is to avoid the resonance between the stay vane and the Kármán vortex, therefore, the difference between the natural frequency of the stay vane and the frequency of Kármán vortex is taken as the main target of the OF. However, the modification to increase the frequency difference could negatively affect the performance of the double row cascade. For example, it may increases the difference of frequency, while enlarge the amplitude of pressure pulsation and the hydraulic energy loss at the same time, which is unexpected. To overcome this problem, penalty terms were added. Firstly, energy loss penalty was added to cut down the hydraulic energy loss between the inlet and outlet caused by recirculation and vortex collision. Then, pressure penalty was brought in to lower the risk of cavitation. Moreover, it was necessary to add a length of Kármán vortex street penalty to prevent the vortex street disturbing the flow field of guide vane. The OF adopted in this paper is inspired by the work developed in [28], which is given by the following expression.

$$
\mathrm{OF}=w_{p}\left(\frac{p_{0}-p}{p_{0}}\right)+w_{l}\left(\frac{l_{0}-l}{l_{0}}\right)+w_{e}\left(\frac{e_{0}-e}{e_{0}}\right)
$$

where $p$ is the average dynamic pressure obtained from the monitoring point, $e$ stands the energy losses between the inlet and the outlet of the computational domain, which was defined in Equation (2), and $l$ is the length of wake behind the stay vane. $p_{0}, l_{0}$ and $e_{0}$ represent for the average dynamic pressure, wake length and energy losses of the original blunt profile respectively. The constants $w_{p} w_{l}$ and $w_{e}$ are weight factors of those variables that are set on values of 2, 1,2 respectively.

$$
e=\frac{P_{\text {in }}-P_{\text {out }}}{\rho g}+\left(\frac{V_{\text {in }}^{2}-V_{\text {out }}^{2}}{2 g}\right)
$$

where $P_{\text {in }}$ stands for the average pressure of the inlet, while $P_{\text {out }}$ is the average pressure of the outlet, $\rho$ is the density of water, $V_{\text {in }}$ and $V_{\text {out }}$ represent the average velocity of the inlet and the outlet respectively.

In addition, an important constraint is added to the OF (Equation (3)) that the difference between frequency of the vortex shedding and the stay vane's natural frequency must be greater than $20 \%$ to avoid the resonance.

$$
f \notin\left[0.8 f_{n 1}, 1.2 f_{n 1}\right] \cap\left[0.8 f_{n 2}, 1.2 f_{n 2}\right] \cap\left[0.8 f_{n 3}, 1.2 f_{n 3}\right]
$$

where $f$ is the vortex shedding frequency obtained in CFD simulations, $f_{n 1}, f_{n 2}, f_{n 3}$ represent the first three natural frequency of the studied stay vane (ignoring the small difference of frequency caused by geometry changes).

\subsubsection{Artificial Neural Networks (ANN)}

Considering the PSO optimization should evaluate a large number of geometries, and such a CFD simulation requires huge computational resources, the computational time of optimization process would be unacceptable. To overcome this problem, researchers such as Pierret [29], Teran [25] and Derakhshan [28] adopted the ANN method to obtain approximated solutions instead of the time-consuming numerical simulations. The ANN is a computational model that can imitate the learning capability of animal brain, which turns out to be very useful in function mappings that have 
multiple inlets and outlets. In this paper, the ANN is established to obtain the characteristics related to a geometry for calculating the OF and the original database obtained from CFD simulations in factorial experiment (60 sets of data for Donaldson trailing edge, 25 sets of data for Arc trailing edge and 25 sets of data for Dove trailing edge) was employed for the ANN's training. Through this approach, the OF can be predicted as an output variable from the input parameters of the geometry, which significantly accelerates the optimization process method. The scheme of the ANN is demonstrated in Figure 5.

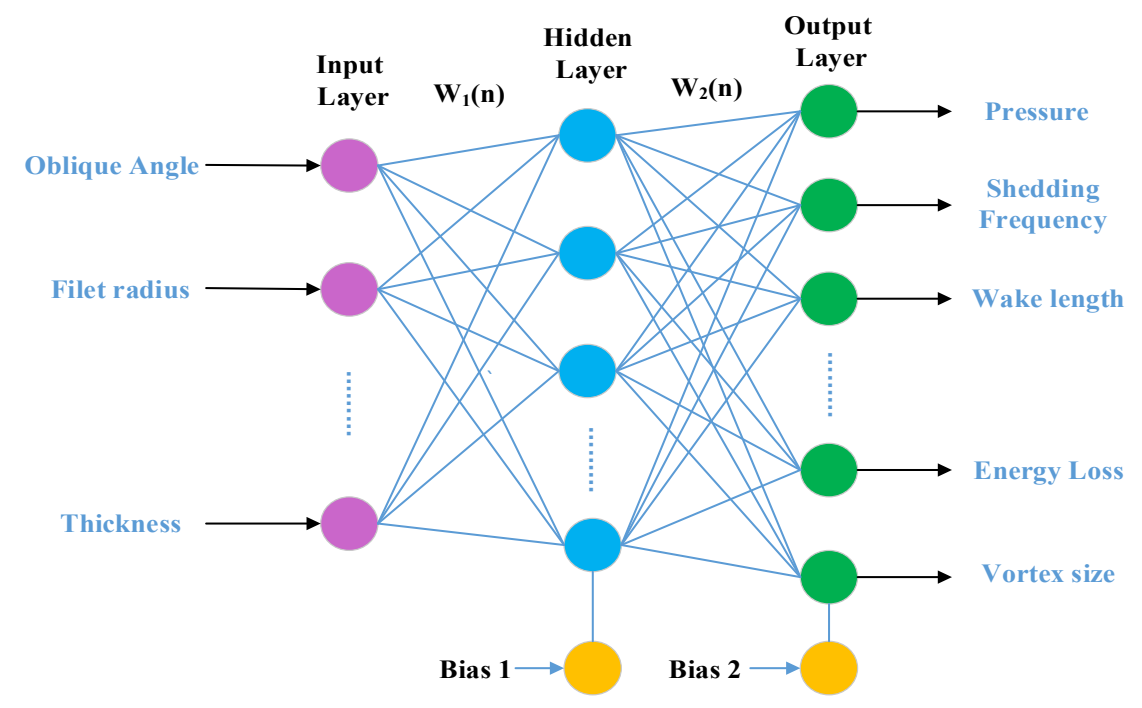

Figure 5. Scheme of artificial neural networks.

\subsubsection{Extreme Learning Machine (ELM)}

The ELM, introduced by Huang et al. [24], is a kind of single hidden layer feed-forward network (SLFN) with a higher learning speed than the traditional neural network. Unlike the traditional neural network learning algorithms (such as back propagation algorithms) need to set a large number of network training parameters, the input weights and hidden biases of ELM are randomly assigned and the output weights are calculated by simply applying generalized inverse operation to the hidden output matrix [30].

Assuming there is a set of $\mathrm{N}$ samples: $\left(x_{i}, \boldsymbol{y}_{i}\right)$ for $i=1,2, \ldots, N$, where $x_{i}=\left[x_{i 1}, x_{i 2}, \ldots, x_{i m}\right]^{T} \in \boldsymbol{R}^{m}$ and $\boldsymbol{y}_{i}=\left[y_{i 1}, y_{i 2}, \ldots, y_{i n}\right]^{T} \in \boldsymbol{R}^{n}$, then, the output of an ELM with $L$ hidden neurons can be expressed as:

$$
f_{L}=\sum_{i=1}^{L} \boldsymbol{\beta}_{i} g\left(\boldsymbol{w}_{i} \cdot \boldsymbol{x}_{j}+b_{i}\right)=\boldsymbol{o}_{j}, j=1, \ldots, N
$$

where $\boldsymbol{w}_{i}=\left[w_{i 1}, w_{i 2}, \ldots, w_{i n}\right]^{T}$ is the input weight vector, $\boldsymbol{\beta}_{i}=\left[\beta_{i 1}, \beta_{i 2}, \ldots, \beta_{i m}\right]^{T}$ is the output weight vector, while $b_{i}$ is the bias and $g(x)$ is the activation function.

The above equation can be simplified as:

$$
H \beta=T
$$

where $\boldsymbol{H}$ is the output matrix of hidden layer, $\beta$ is the weight matrix of output, and $\boldsymbol{T}$ is the matrix of expected output.

$$
\boldsymbol{H}=\left[\begin{array}{c}
\boldsymbol{h}\left(\boldsymbol{x}_{1}\right) \\
\vdots \\
\boldsymbol{h}\left(\boldsymbol{x}_{M}\right)
\end{array}\right]=\left[\begin{array}{ccc}
g\left(w_{1} \cdot x_{1}+b_{1}\right) & \cdots & g\left(\boldsymbol{w}_{L} \cdot \boldsymbol{x}_{1}+b_{L}\right) \\
\vdots & \cdots & \vdots \\
g\left(\boldsymbol{w}_{1} \cdot \boldsymbol{x}_{M}+b_{1}\right) & \cdots & g\left(\boldsymbol{w}_{L} \cdot \boldsymbol{x}_{1}+b_{L}\right)
\end{array}\right]_{M \times L}
$$




$$
\boldsymbol{\beta}=\left[\begin{array}{c}
\boldsymbol{\beta}_{1}{ }^{T} \\
\vdots \\
\boldsymbol{\beta}_{L}{ }^{T}
\end{array}\right]_{L \times n} \text { and } \boldsymbol{T}=\left[\begin{array}{c}
\boldsymbol{t}_{1}{ }^{T} \\
\vdots \\
\boldsymbol{t}_{M}{ }^{T}
\end{array}\right]_{M \times n}
$$

Once the input weights $w_{i}$ and the hidden layer bias $\beta_{i}$ are randomly assigned, the output matrix of the hidden layer is uniquely determined. The training of the neural network can be transformed into solving the following linear system equation:

$$
\|\boldsymbol{H} \hat{\beta}-\boldsymbol{T}\|=\min _{w, b, \beta}\left\|\boldsymbol{H}\left(\boldsymbol{w}_{i}, \boldsymbol{b}_{i}\right) \beta_{i}-\boldsymbol{T}\right\|
$$

Many researches indicate that ELM, compared to traditional ANN, has shown superiority in many aspects, such as learning speed, generalization performance and so on [31-33]. Therefore, the ELM method was introduced in this paper, and comparative test between ELM and ANN was performed. The calculation results of characteristic indicators at the monitoring point by different methods are displayed in Table 2. The results show that ELM has better ability for function mapping than ANN in this case.

\begin{tabular}{|c|c|c|c|c|c|}
\hline Item & dicator & Pressure & Frequency & Wake Length & Energy Loss \\
\hline \multicolumn{2}{|c|}{ CFD } & $73,528 \mathrm{~Pa}$ & $337 \mathrm{~Hz}$ & $0.29 \mathrm{~m}$ & 0.134 \\
\hline \multirow{2}{*}{ Error } & ANN & $-2.0 \%$ & $-3.3 \%$ & $3.6 \%$ & $4.5 \%$ \\
\hline & ELM & $-1.1 \%$ & $-1.2 \%$ & $-3.2 \%$ & $1.2 \%$ \\
\hline
\end{tabular}

Table 2. Comparison between the results of ANN and ELM.

\section{Validation of Computational Model}

\subsection{Experimental Test}

To validate the computational model, an experimental test under different load conditions of the investigated hydropower unit was performed. Since it is difficult to measure the vibration of the stay vane directly, the indirect measurement, which was proved to be competent in [21], was adopted in this research. The location of the monitoring point is on the head cover and presented in Figure 6.

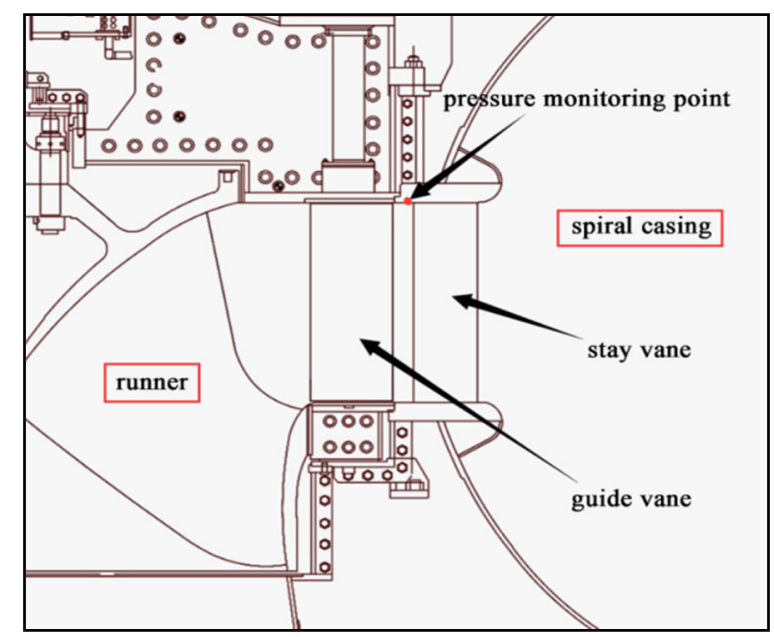

Figure 6. Location of the pressure monitoring point.

The spectrum of the pressure pulsation is displayed in Figure 7. It can be observed that there are significant components $(110-130 \mathrm{~Hz})$ when the load exceeds $170 \mathrm{MW}$, which is considered as the 
consequence of the resonance between the stay vane and the shedding vortex. In order to validate this assumption, modal analysis and CFD simulations were performed to calculate the natural frequency and the shedding vortex frequency of the stay vane respectively.

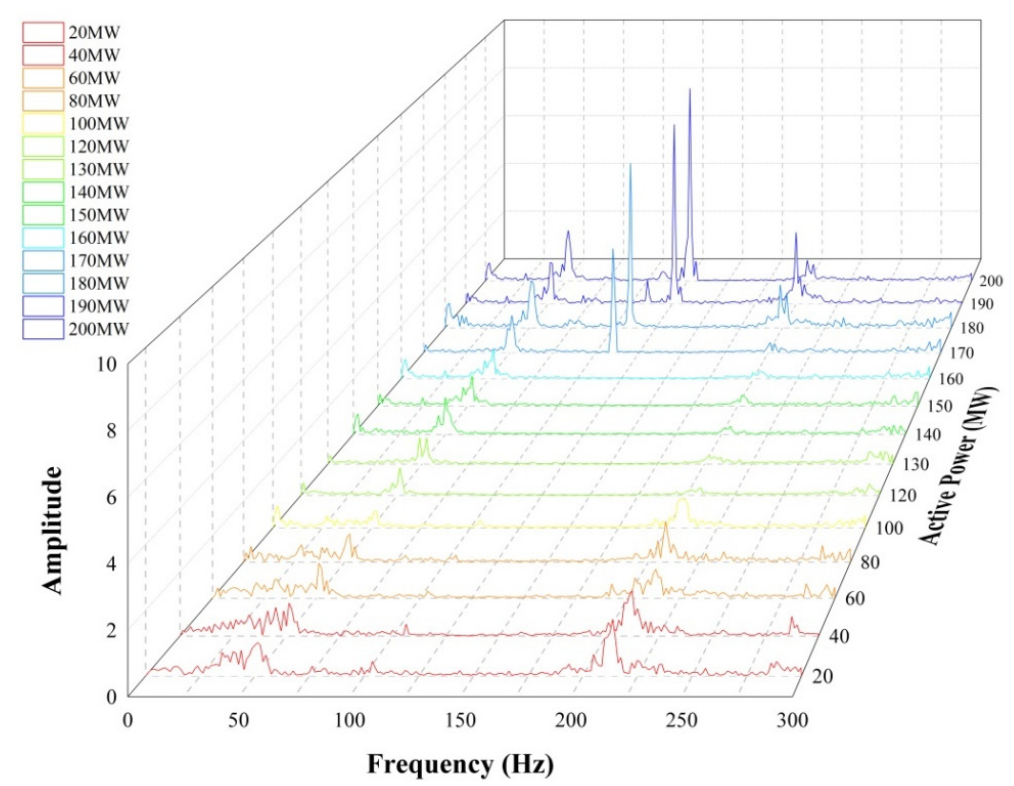

Figure 7. Spectrum of pressure pulsation at different load conditions.

\subsection{Modal Analysis}

A $3 \mathrm{D}$ model of the stay vane corresponded to $1 / 24$ of the stay ring was established for finite element analysis (FEA). The material of the vane is Q235B. Computation results are displayed in Table 3 and Figure 8. It can be noticed that the 1st bending mode frequency $(132.2 \mathrm{~Hz})$ is very close to the significant component measured in the experiment test, which indicates that this mode shape of the stay vane was excited under the high load condition.

Table 3. Natural frequencies calculated by FEA.

\begin{tabular}{ccc}
\hline Natural Frequencies & Dry Mode & Wet Mode \\
\hline 1st bending mode $(\mathrm{Hz})$ & 179.2 & 132.2 \\
1st torsional mode $(\mathrm{Hz})$ & 314.7 & 253.4 \\
2nd bending mode $(\mathrm{Hz})$ & 470.1 & 404.3 \\
\hline
\end{tabular}

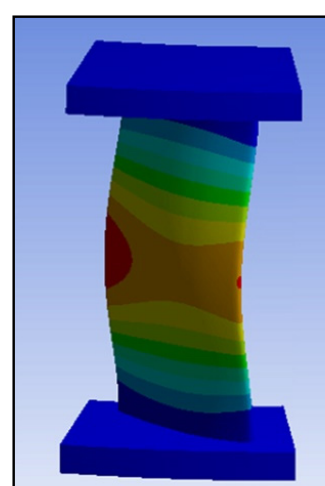

(a)

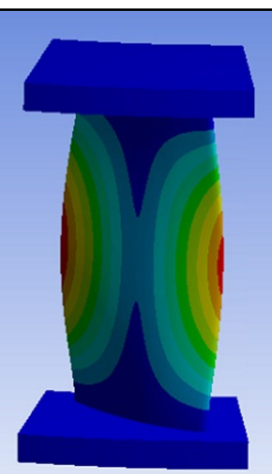

(b)

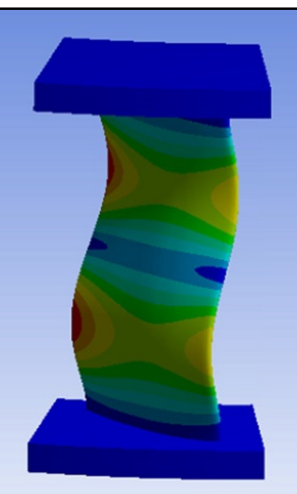

(c)

Figure 8. Stay vane mode shapes: (a) 1st bending, (b) first torsional and (c) second bending. 


\subsection{CFD Simulations}

Two approaches were used to calculate the vortex shedding frequency. The first one is monitoring the pressure pulsation after the stay vane and then obtaining the shedding frequency by signal processing. It can be seen from Figure 9 that the simulation at the $200 \mathrm{MW}$ load condition tends to be stable after $0.12 \mathrm{~s}$, and the dominate frequency of the dynamic pressure is $139.72 \mathrm{~Hz}$.

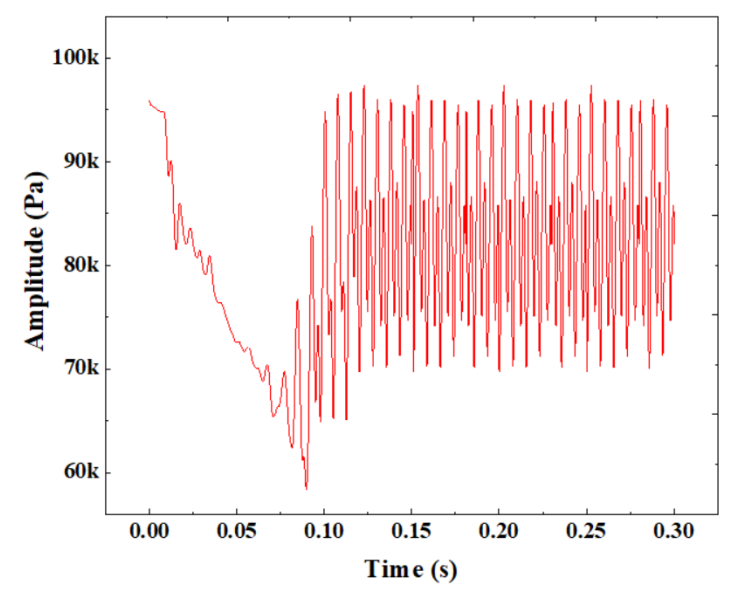

(a)

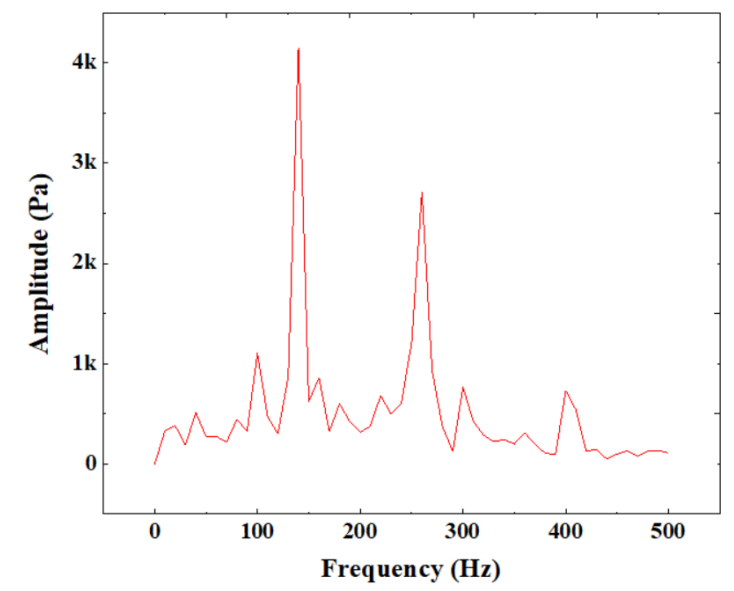

(b)

Figure 9. Results of CFD simulation under the condition of 200 MW. (a) Amplitude of pressure vs. flow time; (b) spectrum of dynamic pressure.

The second method is based on the following empirical equation, which is commonly used to estimate the vortex shedding frequency in practical operation [34].

$$
S_{t}=\frac{D f}{U}
$$

where $f$ is the vortex shedding frequency, $S_{t}$ is the Strouhal number, $U$ denotes the velocity of the flow, and $D$ represent the characteristic length of the trailing edge.

Differ from the traditional method, the average velocity at the separation point and the width of the wake at the separation point which is the sum of the width of trailing edge and the thickness of the boundary layer, were employed instead of the inlet velocity and the width of trailing edge to approach higher accuracy. Considering the Reynolds number is between $3 \times 10^{5}$ and $3 \times 10^{6}$, the Strouhal number is set to 0.25 based on the engineering experience and the work of Shi et al. [35]. The comparison results are shown in Table 4. It can be found that the SST model was not able to 
capture a vortex wake at the low-speed condition and there is no big difference between the results obtained by the LES method and empirical method.

Since the shedding frequency of $174 \mathrm{MW}$ is close to the 1st natural frequency of the stay vane in water $(132.2 \mathrm{~Hz})$, it can be concluded that the resonance between the stay vane and the shedding vortex at high load condition is the reason for the undesirable vibration and the fatigue damage.

Table 4. Comparison of results obtained by different methods.

\begin{tabular}{ccccccc}
\hline \multirow{2}{*}{ Conditions } & Guide Vane Opening $\left(^{\circ}\right)$ & $\mathbf{1 6}$ & $\mathbf{2 0}$ & $\mathbf{2 4}$ & $\mathbf{2 8}$ & $\mathbf{3 2}$ \\
\cline { 2 - 6 } & Unit Output $(\mathrm{MW})$ & 100 & 144 & 174 & 200 & 215 \\
& Head $(\mathrm{m})$ & 78.5 & 78.5 & 78.5 & 78.5 & 78.5 \\
\hline \multirow{2}{*}{ LES Method } & Amplitude of Dynamic Pressure $(\mathrm{Pa})$ & 12,974 & 34,875 & 67,568 & 83,013 & 11,834 \\
& Frequency of Dynamic Pressure $(\mathrm{Hz})$ & 82.4 & 100.1 & 122.8 & 139.7 & 157.3 \\
\hline \multirow{2}{*}{ SST Method } & Amplitude of dYnamic Pressure $(\mathrm{Pa})$ & 11,784 & 32,578 & 49,735 & 72,378 & 87,742 \\
& Frequency of Dynamic Pressure $(\mathrm{Hz})$ & - & - & 112.7 & 150.2 & 169.7 \\
\hline \multirow{2}{*}{ Empirical Method } & Average Velocity (m/s) & 6.938 & 8.745 & 10.927 & 12.157 & 14.072 \\
& Width of Wake (m) & 0.0198 & 0.0209 & 0.0215 & 0.0212 & 0.0214 \\
& Calculated Value of Frequency $(\mathrm{Hz})$ & 87.60 & 104.61 & 127.06 & 143.36 & 164.39 \\
\hline
\end{tabular}

\section{Results and Discussion}

\subsection{Results of Factorial Experiments}

In order to study the effect of each factor determining the trailing edge profile on the performance of stay vane, factorial experiments were conducted in CFD simulations. The results were demonstrated and discussed in the following parts.

Thickness: By cutting or extending the profile of trailing edge, a set of simulations was performed to investigate the influence of the trailing edge thickness. As shown in Figure 10, the alternate vortexes detached from upper and lower corners of the trailing edge and encountered in the wakes behind the stay vane. It can be observed that the detach velocity is larger and the development space of the vortex is narrower in the case of thinner trailing edge, leading to a more violent collision between the vortexes and accelerating the decay process of the Kármán vortex street. Therefore, with the decrease of the thickness of the trailing edge, the vortex shedding frequency increases, while the amplitude of the pressure and the length of wake decrease.

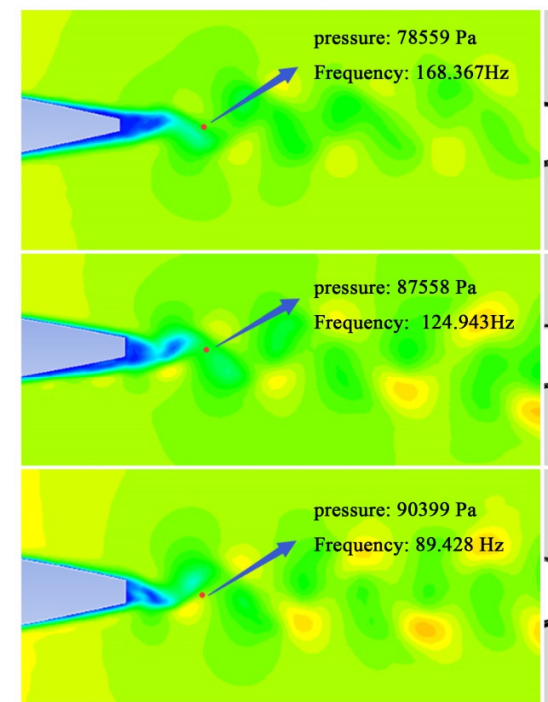

a) Countour of velocity

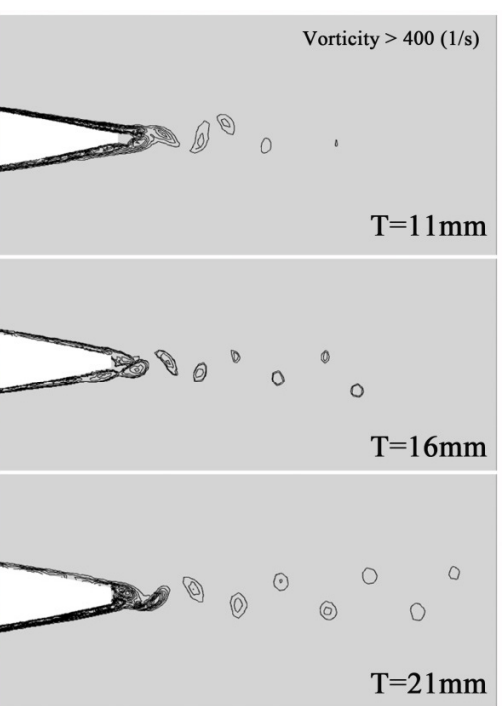

b) Countour of vorticity

Figure 10. Comparison of trailing edge with different thickness. 
Oblique Angle: The oblique angle denoted in Figure 3 is the angle between the upper and the lower sides of the trailing edge. With the increase of oblique angle, the difference of velocity between the flows from upper and lower sides increased, and the development space of vortex reduced which is equivalent to the effect of shortening the trailing edge thickness. It can be observed from Figure 12a that the size of vortexes became smaller and the wakes are shorter with the increase of the oblique angle. Besides, a significant reduction of pressure pulsation and an increase of shedding frequency were found as well, which is in a good agreement with the research of Ref. [15].

Fillet radius: It is found in the practical engineering applications that the VIV can be reduced to some extent after rounding at corners. The effect of corner smoothing at the upper side of the trailing edge is similar to the oblique trailing edge design with smaller hydraulic losses.

Shape: The comparison of different shapes is displayed in (Figure 11b). In the Dove and Arc design, the vortexes were generated in the cavity of the trailing edge. The narrow space caused a violent collision of vortex, speeding up the process of the collapse of Kármán vortex. In the Donaldson design, the vortexes from the lower side roll up and encounter the vortexes from the upper side having a violent collision. In this way, the energy of the Kármán vortex street is cut down significantly while the shedding frequency increases at the same time.

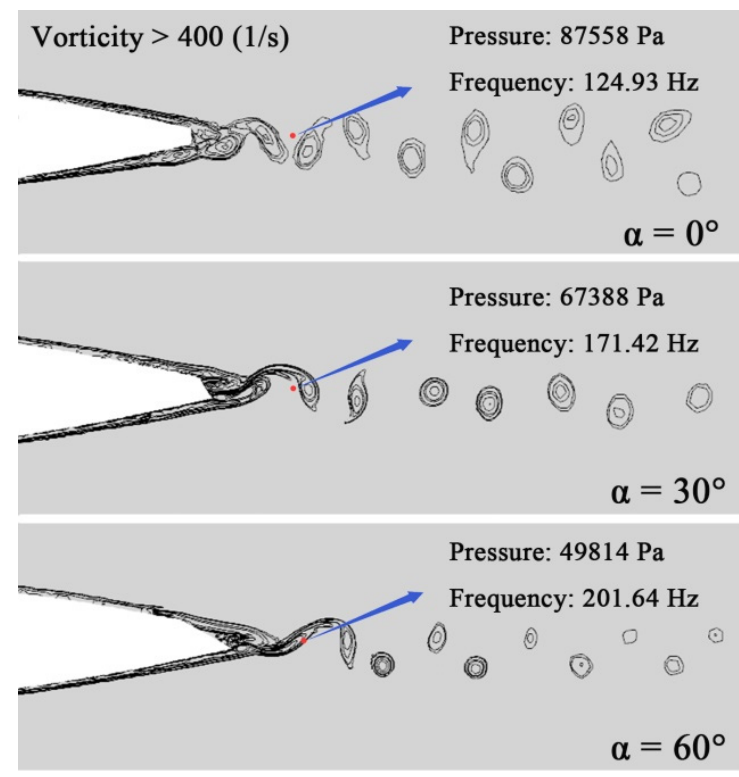

a) Different oblique angle

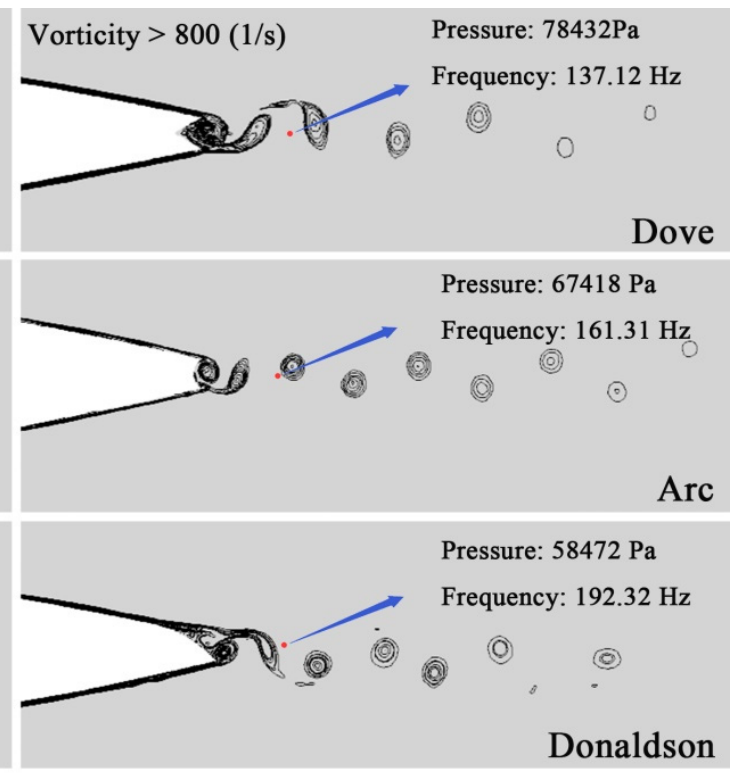

b) Different shape design

Figure 11. Results with different trailing edges.

It can be inferred from the results of the above factorial experiments that the shedding frequency and energy of the Karman vortex can be controlled by changing the trailing edge configuration of the stay vane profile to achieve better performance in the case of avoiding resonance.

\subsection{Verification of Optimized Geometries}

After the optimization process with ELM and PSO, three results were obtained from the three kinds of profiles of the stay vane. The first verification was carried out in CFD to evaluate the performance of these geometries. The profiles of the optimized trailing edge and corresponding characteristic calculated in CFD simulations are shown in Table 5. With the application of the constraint in the OF, the shedding frequency of Kármán vortex was obviously increased and the difference between the vortex shedding frequency and the first three natural frequency was big enough to avoid resonance. It can be observed that with the decrease in the thickness of the trailing edge, all the indicators of 
vane performance are improved, therefore, the thickness of these three results are optimized to the minimum thickness of $10 \mathrm{~mm}$.

Table 5. The comparison of optimized geometries.

\begin{tabular}{lccccc}
\hline \multicolumn{1}{c}{ Item } & Profiles of Optimized Trailing Edge & $\begin{array}{c}\text { Dynamic } \\
\text { Pressure }\end{array}$ & $\begin{array}{c}\text { Shedding } \\
\text { Frequency }\end{array}$ & Wake Length & Energy Losses \\
\hline Original shape & & $83,013 \mathrm{~Pa}$ & $139.7 \mathrm{~Hz}$ & $0.567 \mathrm{~m}$ & 0.145 \\
\hline A: Donaldson & & & & & \\
\hline \\
B: Arc
\end{tabular}

The wakes length after the stay vane of Dove and Arc profiles is significantly shorter, which means that the Kármán vortex decays faster after the collision at the cavity of the tail. It is considered that the narrow cavity limits the growing space of vortex and intensifies the collision between the two counter-rotating rows of swirls, which would increase the hydraulic losses and accelerate the decays process. Since all the indicators of the performance of Donaldson trailing edge were improved, this kind of profile was considered as the best solution.

In order to evaluate the risk of fatigue damage under the circumstances of no resonance, the Goodman criterion was employed [36]. The results of CFD simulations were imported in a structural simulation of the stay vane to calculate the distribution of Von Mises stress, which is demonstrated in Figure 12, where the maximum stress is marked in places sensitive to fatigue damage, and this conclusion is coincided with the location where the crack appeared in the practical operation (The connection between the stay vane and the stay ring). The fluctuating dynamic pressure of the maximum point of the stress on the stay vane was found using CFD and structural coupled transient simulation (Figure 13). The information (the peak value and the valley value) at the point of maximum stress was used to calculate the fatigue life. The stay vane material is Q235B; its fatigue properties are described in Ref. [37].

The stress amplitude transformed from asymmetric stress to symmetrical stress is $6.2 \mathrm{Mpa}$. The stay vane's fatigue damage coefficient was calculated as 0.023 when the survival rate is $99 \%$ and the unit annual utilization factor is 0.83 . In the end, the obtained fatigue life was 43.5 years, which means the stay vane can provide good safety factor without resonance. 


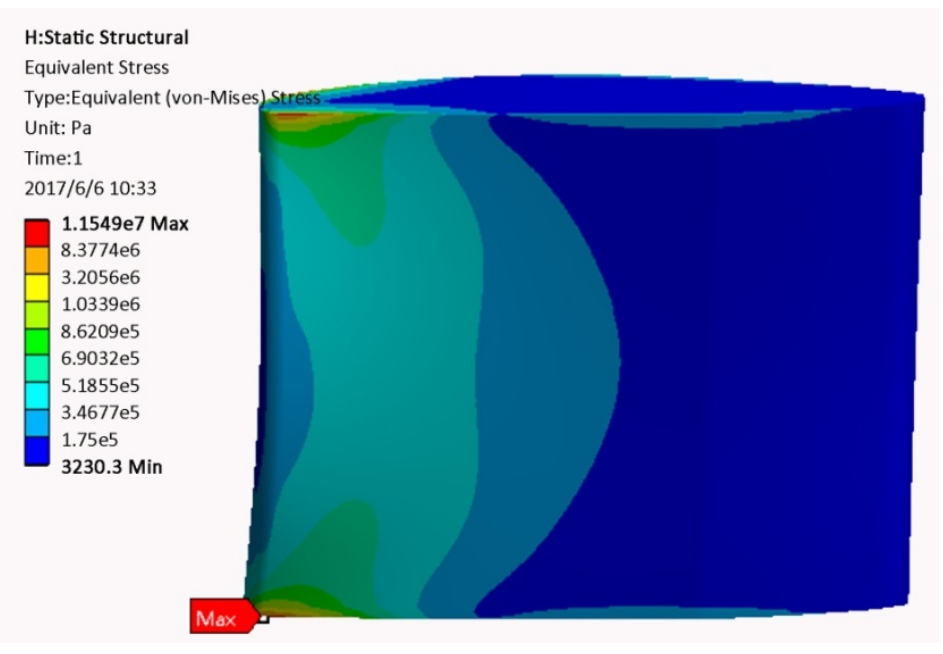

Figure 12. Von Mises stress distribution of the stay vane.

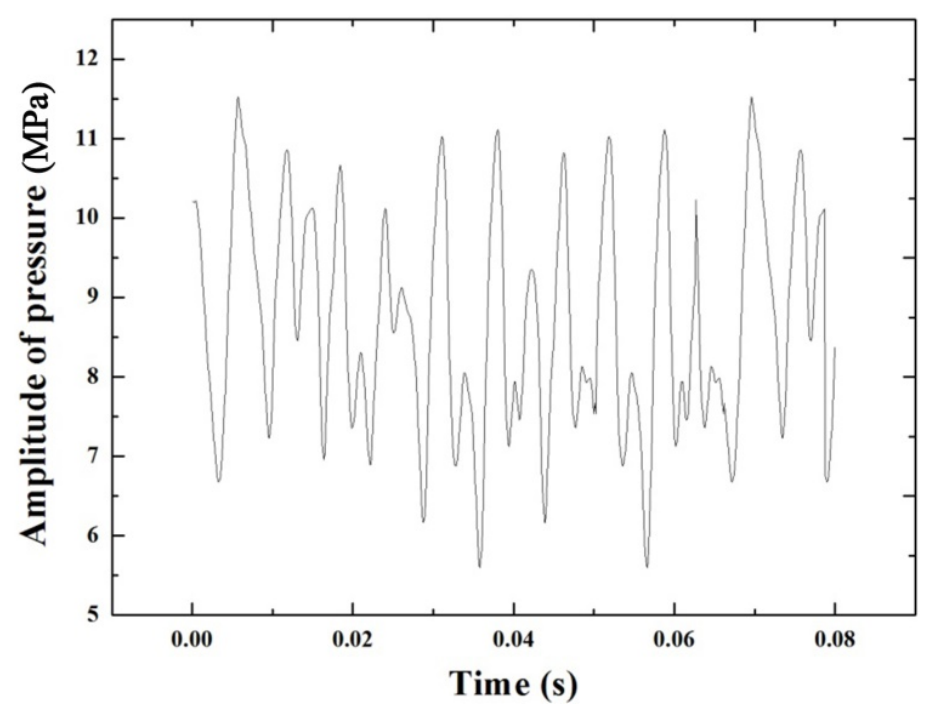

Figure 13. Dynamic pressure of the maximum point on stay vane vs. time.

\section{Conclusions}

In this paper, an intelligent optimization method for the trailing edge profile of stay vane, which is based on CFD simulation, ELM and PSO, was proposed to reduce the undesired vibration and improve the performance of the stay vane. Four factors (thickness, oblique angle, fillet radius, shape) were introduced to define the profile of the stay vane trailing edge. Factorial experiments of these factors were performed and the results were used to establish a database for ELM training. At last, PSO was utilized to find the best solution under the given constraint in OF. Different from the traditional optimization method, it does not give an optimization scheme and then verify its superiority, but find the optimal solution considering the actual needs in all optimization programs. By using this method, the optimal geometry of the stay vane can be efficiently obtained considering practical engineering requirement, and the design costs can be reduced greatly.

In the end, an optimized profile of the stay vane with a Donaldson trailing edge was chosen as the best solution. The resonance between the shedding vortex and the stay vane was eliminated, while other indicators of performance were improved at the same time, such as the dynamic pressure at the tail of the vane was decreased by $11.7 \%$, and the hydraulic energy losses was cut down by $17.9 \%$. 
Verifications such as CFD simulations, structural analysis and fatigue analysis were carried out and the results allowed one to draw the conclusion that the optimized stay vane will perform well.

Acknowledgments: This work was supported by the National Key R\&D Program of China (Nos. 2016YFC0402205, 2016YFC0401910) and the National Natural Science Foundation of China (NSFC) (No. 51079057).

Author Contributions: Xuanlin Peng and Jianzhong Zhou conceived and designed the experiments, Ruhai Li and Yanhe $\mathrm{Xu}$ performed the simulations; Chu Zhang analyzed the data; Xuanlin Peng and Diyi Chen wrote the paper.

Conflicts of Interest: The authors declare no conflicts of interest.

\section{Index of Acronyms}

$\begin{array}{ll}\text { VIV } & \text { Vortex-Induced Vibration } \\ \text { FEM } & \text { Finite Element Method } \\ \text { PSO } & \text { Particle Swarm Optimization } \\ \text { ELM } & \text { Extreme Learning Machine } \\ \text { CFD } & \text { Computational Fluid Dynamics } \\ \text { PIV } & \text { Particle Image Velocimetry } \\ \text { ANN } & \text { Artificial Neural Network } \\ \text { LES } & \text { Large Eddy Simulation } \\ \text { DNS } & \text { Direct Numerical Simulations } \\ \text { FVM } & \text { Finite Volume Method } \\ \text { SIMPLE } & \text { Semi-Implicit Method For Pressure-Linked Equations } \\ \text { MUSL } & \text { Monotone Upstream-Centered Schemes For } \\ \text { OF } & \text { Conservation Laws }\end{array}$

\section{Nomenclature}

\begin{tabular}{ll}
$r$ & Radius of Fillet \\
$R$ & Radius of Arc \\
$T$ & Thickness \\
$p$ & Average Dynamic Pressure of Monitoring Point \\
$e$ & Energy Losses Between The Inlet And The Outlet \\
$l$ & Length of Wake \\
$p_{0}$ & Dynamic Pressure of Original Blunt Profile \\
$l_{0}$ & Energy Losses of Original Blunt Profile \\
$e_{0}$ & Wake Length of Original Blunt Profile \\
$w_{p}$ & Weight Factor of p \\
$w_{l}$ & Weight Factor of l \\
$w_{e}$ & Weight Factor of e \\
$P_{i n}$ & Average Pressure of The Inlet \\
$P_{\text {out }}$ & Average Pressure of The Inlet \\
$\rho$ & Density of Water \\
$V_{i n}$ & Average Velocity of Inlet \\
$V_{\text {out }}$ & Average Velocity of Outlet \\
$f$ & Vortex Shedding Frequency \\
$\boldsymbol{H}$ & Output Matrix of Hidden Layer \\
$\beta$ & Weight Matrix of Output \\
$T$ & Matrix of Expected Output \\
$w_{i}$ & Input Weights \\
$\beta_{i}$ & Hidden Layer Bias \\
$S_{t}$ & Strouhal Number \\
$U$ & Velocity of The Flow \\
$D$ & Characteristic Length of The Trailing Edge \\
& \\
\hline
\end{tabular}




\section{References}

1. Koirala, R.; Thapa, B.; Neopane, H.P.; Zhu, B.S. A review on flow and sediment erosion in guide vanes of Francis turbines. Renew. Sustain. Energy Rev. 2017, 75, 1054-1065. [CrossRef]

2. Pankanin, G.L.; Kulińczak, A.; Berliński, J. Investigations of Karman vortex street using flow visualization and image processing. Sens. Actuators A-Phys. 2007, 138, 366-375. [CrossRef]

3. Bao, Y.; Huang, C.D.; Zhou, J.H.; Han, Z.L. Two-degree-of-freedom flow-induced vibrations on isolated and tandem cylinders with varying natural frequency ratios. J. Fluids Struct. 2012, 35, 50-75. [CrossRef]

4. Han, X.X.; Lin, W.; Tang, Y.H.; Zhao, C.B.; Sammut, K. Effects of natural frequency ratio on vortex-induced vibration of a cylindrical structure. Comput. Fluids 2015, 110, 62-76. [CrossRef]

5. Jain, A.; Modarres-Sadeghi, Y. Vortex-induced vibrations of a flexibly-mounted inclined cylinder. J. Fluids Struct. 2013, 43, 28-40. [CrossRef]

6. Trivedi, C.; Cervantes, M.J. Fluid-structure interactions in Francis turbines: A perspective review. Renew. Sustain. Energy Rev. 2017, 68, 87-101. [CrossRef]

7. Viviano, A.; Musumeci, R.E.; Foti, E. Interaction between waves and gravity currents: Description of turbulence in a simple numerical model. Environ. Fluid Mech. 2017, 4, 1-32. [CrossRef]

8. Musumeci, R.E.; Viviano, A.; Foti, E. Influence of Regular Surface Waves on the Propagation of Gravity Currents: Experimental and Numerical Modeling. J. Hydraul. Eng. 2017, 143, 04017022. [CrossRef]

9. Viviano, A.; Musumeci, R.E.; Foti, E. A nonlinear rotational, quasi-2DH numerical model for spilling wave propagation. Appl. Math. Model. 2015, 39, 1099-1118. [CrossRef]

10. Zhang, G.Q.; Ji, L.C. Investigation of two degrees of freedom on vortex-induced vibration under the wake interference of an oscillating airfoil. Acta Astronaut. 2017, 133, 423-435. [CrossRef]

11. Thapa, B.S.; Trivedi, C.; Dahlhaug, O.G. Design and development of guide vane cascade for a low speed number Francis turbine. J. Hydrodyn. 2016, 28, 676-689. [CrossRef]

12. Tian, W.; Mao, Z.; Zhao, F. Design and Numerical Simulations of a Flow Induced Vibration Energy Converter for Underwater Mooring Platforms. Energies 2017, 10, 1427. [CrossRef]

13. Adhikari, R.C.; Vaz, J.; Wood, D. Cavitation Inception in Crossflow Hydro Turbines. Energies 2016, 9, 237. [CrossRef]

14. Wu, J.; Shimmei, K.; Tani, K.; Niikura, K.; Sato, J. CFD-Based Design Optimization for Hydro Turbines. J. Fluids Eng. 2007, 129, 159-168. [CrossRef]

15. Bahrami, S.; Tribes, C.; Fellenberg, S.V.; Vu, T.C.; Guibault, F. Multi-Fidelity Design Optimization of Francis Turbine Runner Blades. In Proceedings of the 27th IAHR Symposium Hydraulic Machinery and Systems, Montreal, QC, Canada, 22-26 September 2014; p. 10.

16. Buono, D.; Frosina, E.; Mazzone, A.; Cesaro, U.; Senatore, A. Study of a Pump as Turbine for a Hydraulic Urban Network Using a Tridimensional CFD Modeling Methodology. Energy Procedia 2015, 82, $201-208$. [CrossRef]

17. Pugliese, F.; De Paola, F.; Fontana, N.; Giugni, M.; Marini, G. Experimental characterization of two pumps as turbines for hydropower generation. Renew. Energy 2016, 99, 180-187. [CrossRef]

18. Frosina, E.; Buono, D.; Senatore, A. A Performance Prediction Method for Pumps as Turbines (PAT) Using a Computational Fluid Dynamics (CFD) Modeling Approach. Energies 2017, 10, 103. [CrossRef]

19. Zobeiri, A.; Ausoni, P.; Avellan, F.; Farhat, M. How oblique trailing edge of a hydrofoil reduces the vortex-induced. J. Fluids Struct. 2012, 32, 78-89. [CrossRef]

20. Yao, Z.F.; Wang, F.J.; Dreyer, M.; Farhat, M. Effect of trailing edge shape on hydrodynamic damping for a hydrofoil. J. Fluids Struct. 2014, 51, 189-198. [CrossRef]

21. Neto, A.D.; Saltara, F. Study of Stay Vanes Vortex-Induced Vibrations with different Trailing-Edge Profiles Using CFD. Int. J. Fluid Mach. Syst. 2009, 2, 363-374. [CrossRef]

22. Vu, T.C.; Nennemann, B.; Ausoni, P.; Farhat, M.; Avellan, F. Unsteady CFD prediction of von Kármán vortex shedding in hydraulic turbine stay vanes. In Proceedings of the Hydro 2007, Granada, Spain, 15-17 October 2007.

23. Neto, A.D.; Gissoni, H.; Gonçalves, M.; Cardoso, R.; Jung, A.; Meneghini, J. Engineering diagnostics for vortex-induced stay vanes cracks in a Francis turbine. In IOP Conference Series: Earth and Environmental Science; Fluid Structure Interactions; IOP Publishing: Bristol, UK, 2016; Volume 49. 
24. Eltvik, M.; Thapa, B.S.; Dahlhaug, O.G.; Gjosater, K. Numerical analysis of effect of design parameters and sediment erosion on a Francis runner. In Proceedings of the Fourth International Conference on Water Resources and Renewable Energy Development in Asia, Chiang Mai, Thailand, 26-27 March 2012.

25. Teran, L.A.; Larrahondo, F.J.; Rodríguez, S.A. Performance improvement of a 500-kW Francis turbine based on CFD. Renew. Energy 2016, 96, 977-992. [CrossRef]

26. Anup, K.C.; Lee, Y.H.; Thapa, B. CFD study on prediction of vortex shedding in draft tube of Francis turbine and vortex control techniques. Renew. Energy 2016, 86, 1406-1421.

27. Kostrewa, K.; Van den Braembussche, R.A.; Alsalihi, Z. Optimization of Radial Turbines by Means of Design of Experiment. Available online: https://www.vki.ac.be/download/dcsummaries/02-03/17_ kostrzewapr200317.pdf (accessed on 17 November 2017).

28. Derakhshan, S.; Mostafavi, A. Optimization of GAMM Francis turbine runner. World Acad. Sci. Eng. Technol. 2011, 59, 487-494.

29. Pierret, S.; Van den Braembussche, R.A. Turbomachinery blade design using Navier-Stokes solver and artificial neural network. ASME J. Turbomach. 1999, 121, 326-332. [CrossRef]

30. Huang, G.B.; Zhu, Q.Y.; Siew, C.K. Extreme learning machine: A new learning scheme of feedforward neural networks. In Proceedings of the IEEE International Joint Conference on Neural Networks, Budapest, Hungary, 25-29 July 2005; Volume 2, pp. 985-990.

31. Yadav, B.; Ch, S.; Mathur, S.; Adamowski, J. Estimation of in-situ bioremediation system cost using a hybrid Extreme Learning Machine (ELM)-particle swarm optimization approach. J. Hydrol. 2016, 543, 373-385. [CrossRef]

32. Zhang, C.; Zhou, J.; Li, C.; Fu, W.; Peng, T. A compound structure of ELM based on feature selection and parameter optimization using hybrid backtracking search algorithm for wind speed forecasting. Energy Convers. Manag. 2017, 143, 360-376. [CrossRef]

33. Peng, T.; Zhou, J.; Zhang, C.; Zheng, Y. Multi-step ahead wind speed forecasting using a hybrid model based on two-stage decomposition technique and AdaBoost-extreme learning machine. Energy Convers. Manag. 2017, 153, 589-602. [CrossRef]

34. Li, C.; Yang, W.J.; Xu, X.H.; Wang, J.Y.; Wang, M.; Xu, L.Y. Numerical investigation of fish exploiting vortices based on the Kármán gaiting model. Ocean Eng. 2017, 140, 7-18. [CrossRef]

35. Shi, L.; Yu, Z.B.; Jaworski, A.J. Investigation into the Strouhal numbers associated with vortex shedding from parallel-plate thermoacoustic stacks in oscillatory flow conditions. Eur. J. Mech. B Fluids 2011, 30, $206-217$. [CrossRef]

36. Nie, L.G.; Zhang, M.X.; Zhu, L.B.; Pang, J.C.; Yao, G.; Mao, Y.X.; Chen, M.; Zhang, Z.F. Fatigue life prediction of motor-generator rotor for pumped-storage plant. Eng. Fail. Anal. 2017, 79, 8-24. [CrossRef]

37. Wang, J.J.; Guo, W.G.; Gao, X.S.; Su, J. The third-type of strain aging and the constitutive modeling of a Q235B steel over a wide range of temperatures and strain rates. Int. J. Plast. 2015, 65, 85-107. [CrossRef] 